\title{
Orthopaedic education: a COVID-driven evolution
}

\author{
Alex Trompeter ${ }^{1,2,3}$ \\ Published online: 12 June 2021 \\ (c) The Author(s), under exclusive licence to Springer-Verlag France SAS, part of Springer Nature 2021
}

As we slowly move through 2021 and the COVID pandemic continues, it is important that we do not lose sight of the need to maintain our orthopaedic knowledge and continue our education. As surgeons and healthcare practitioners involved in the management of acutely injured patients, we have a responsibility to remain current and up to date in our knowledge and skills. The process of learning should never stop, and it is vital to recognise the continual evolution in care and decision making that goes on around us.

The pandemic has challenged our ability to meet face to face. Gone are the conferences, courses, workshops and simulation laboratories. Much learning has moved online. The COVID-19 pandemic has highlighted several challenges in how to deliver orthopaedic education, especially the physical aspects of surgical skills training and knowledge updates [1-14]. None the less, the orthopaedic community has risen to the challenge.

But where do we go next with our continual professional development (CPD) and education in orthopaedics? At some point we will come out the other side of this pandemic and need to have direction and purpose in where we are going. We will need to regroup, dust ourselves down, and come back bigger and stronger than before. This applies across the whole scope of our practice including education. Clearly we will have learnt lessons along the way and there is no doubt a huge amount of positive change that we can capture from the changes enforced upon us during the pandemic.

It has come as no surprise that online didactic lectures hold little value, and that interactive sessions focussing on active learning, peer instruction and discussion environment as described by Mazur [15-17] are far more effective. This interaction can be achieved online, and indeed a huge

Alex Trompeter

a.trompeter@nhs.net

1 Department of Trauma and Orthopaedics, St George's University Hospital, London, London, UK

2 St George's University of London, London, UK

3 EJOST, Paris, France number of Industry supported webinars have offered some fantastic open forum live discussion sessions.

The biggest challenge is how to replicate the immersive case-based experience of simulation and cadaveric laboratories in an online forum. The benefits of active learning are recognised in orthopaedic education utilising case discussion and simulation [18-20] The value of interactive case preparation and the importance of mental imagery has previously been described in orthopaedic surgery [21] as are the benefits of cadaveric simulation [22, 23]. Surgical and clinical scenario simulation is commonly used in orthopaedics [24] but transferring that to the online world remains a challenge.

But what if we have webinar fatigue? What if there is simply not enough time in your day for yet another Zoom or Teams discussion session? Where do you turn for that update and education fix? We used to sit down and read a journal or text with a cup of coffee... perhaps we must not lose sight of that. Quiet individual time spent reading, contemplating and cogitating is vital. It allows us to distil our thoughts at our own pace, and synthesise our own opinions. The bright noises and lights of the online world are here to stay and hold huge benefit, but we must also hold onto aspects of the past that offer so much more. Reading has, and always will be, a hugely personal experience and is just as important as all the other education tools we now have.

As such, this special trauma focussed volume of EJOST has been put together for you, the orthopaedic surgeon or healthcare practitioner who covers on call commitments and manages acutely injured adults and children. The aim is to provide you an update on certain trauma conditions you may regularly manage but perhaps have not had an update in a while. At the same time some of the articles offer a modern insight into the management of more specific or nuanced injuries and conditions, or pathways and processes. There are three main themes to these invited articles-those that look at specific adult fractures, those focussing on paediatric injuries, a selection of work focussing on complex reconstructive issues, and a group of articles looking at some of our fundamental orthopaedic principles. 
For those wanting an update on some specific adult trauma topics, Pearce et al. [25] have provided a fantastic overview on the management of atypical femoral fractures. These are increasingly common occurrences in our daily practice and can prove challenging to treat. Avoiding failure and varus malreduction are key to success and the article provides an excellent review of the most current evidence as well as some sensible tips and tricks. Updates in the treatment of other common conditions such as elderly pelvic and acetabular injuries [26, 27] are also covered. These injuries have seen significant shifts in their management approaches over the last two decades. The key is early weightbearing and rehabilitation, something echoed in the discussion on periprosthetic femoral fractures [28] also provided. I also recommend an update on young adult hip fractures, where we have seen continual argument in the literature over the last few years [29]. Is there really a need for open reduction in these injuries? Furthermore, we must be conscious of the risks of complications associated with both injuries and their treatment. The Edinburgh group have provided an in depth analysis of the risks of carpal tunnel syndrome associate with distal radius fractures-one of the most common injuries we treat [30].

Many of us manage paediatric trauma as part of our on call commitment, yet are not full time paediatric orthopaedic specialists. A suite of articles are provided in this volume looking at common paediatric fractures and providing up to date management algorithms, and looking at longer term outcomes [31-34]. I have no doubt these articles will be particularly informative to those who have an understandable anxiety when faced with an injured child out of hours or on a weekend.

For those interested in complex trauma and management of trauma complications you are not to be disappointed. Iliadis et al. [35] have brought together the latest advice and guidance on the management of fracture related infection. There has been a huge amount of development in this field in the last 5 years, with a recognition of the need for specialist practices in this field and the vital importance of multidisciplinary working. Historically those who suffered infections after fracture fixation were often cast onto the orthopaedic scrapheap, destined for a life of misery or amputation. However, we are increasingly seeing excellent results with aggressive multidisciplinary management whereby union without infection can be readily achieved. Updates on gunshot injuries [36], bone loss in the upper limb [37], and novel techniques in the management of long bone non-union [38] are also presented.

Finally, we have a group of articles focussing on our orthopaedic trauma practice in general. The UK has been an exemplar in the development of internationally recognised trauma guidelines. These British Orthopaedic Standards for Trauma (BOASTs) have become a vital component in the drive to improve performance in specific aspects of trauma and the article by Griffiths [39] details the fascinating journey of how these came about and the impact they have had on UK trauma practice. Two other areas of orthopaedics where we probably give little thought are also considered in this special trauma edition: the use of a tourniquet and the use of ionising radiation. Have you ever stopped to think of the dangers to yourself in the OR with respect to the use of $\mathrm{x}$-rays over a whole career? If not, then I recommend you read the article by Raza [40] which provides a comprehensive review of the rules and regulations around the use of ionising radiation and makes us aware of the simple but effective measures we should be taking in the OR to protect ourselves. Similarly, I suspect many surgeons use a tourniquet out of habit. Yet the evidence supporting tourniquet use is lacking, and indeed there is an increasing body of literature suggesting they may do harm, or at least offer no benefit to the patient in terms of outcome. Can we justify the use of a device that carries risk of harm to the patient, and only offers perceived benefit to the operating surgeon? [41].

I hope you do find time for a quiet moment of contemplative reading. More importantly I am hopeful that the articles presented in this special edition will pique your interest, provide you the updates you need, or make you challenge traditional practice. Our educational journey never stops, and this edition of EJOST is another step on the path to improving our knowledge such that we can improve the care we deliver to our trauma patients.

\section{References}

1. An TW, Henry JK, Igboechi O et al (2020) How are orthopaedic surgery residencies responding to the COVID-19 pandemic? An assessment of resident experiences in cities of major virus outbreak. J Am Acad Orthop Surg 28(15):E679-E685. https://doi. org/10.5435/JAAOS-D-20-00397

2. Kogan M, Klein SE, Hannon CP, Nolte MT (2020) Orthopaedic education during the COVID-19 pandemic. J Am Acad Orthop Surg 28(11):e456-e464. https://doi.org/10.5435/ JAAOS-D-20-00292

3. Mauffrey C, Trompeter A (2020) Lead the way or leave the way: leading a Department of Orthopedics through the COVID-19 pandemic. Eur J Orthop Surg Traumatol 30(4):555-557. https://doi. org/10.1007/s00590-020-02670-x

4. Khan H, Williamson M, Trompeter A (2020) The impact of the COVID-19 pandemic on orthopaedic services and training in the UK. Eur J Orthop Surg Traumatol. https://doi.org/10.1007/ s00590-020-02748-6

5. Tahmassebi R, Bates P, Trompeter A et al (2020) Reflections from London's Level-1 Major Trauma Centres during the COVID crisis. Eur J Orthop Surg Traumatol 30(6):951-954. https://doi.org/ 10.1007/s00590-020-02724-0

6. Hueston WJ, Petty EM (2020) The impact of the COVID-19 pandemic on medical student education in Wisconsin. Wis Med J 119(2):80-82 
7. Megaloikonomos PD, Thaler M, Igoumenou VG et al (2020) Impact of the COVID-19 pandemic on orthopaedic and trauma surgery training in Europe. Int Orthop 44(9):1611-1619. https:// doi.org/10.1007/s00264-020-04742-3

8. Schwartz A, Wilson J, Boden S, Moore T, Bradbury T, Fletcher $\mathrm{N}$ (2020) Managing resident workforce and education during the COVID-19 pandemic: evolving strategies and lessons learned. JB JS open access 5(2):e0045. https://doi.org/10.2106/JBJS.OA.20. 00045

9. Essilfie AA, Hurley ET, Strauss EJ, Alaia MJ (2020) Resident, fellow, and attending perception of e-learning during the COVID19 pandemic and implications on future orthopaedic education. J Am Acad Orthop Surg 28(19):e860-e864. https://doi.org/10.5435/ JAAOS-D-20-00579

10. Bodansky D, Thornton L, Sargazi N, Philpott M, Davies R, Banks J (2021) Impact of COVID-19 on UK orthopaedic training. Bull R Coll Surg Engl 103(1):38-42. https://doi.org/10.1308/rcsbull. 2021.11

11. Plancher KD, Shanmugam JP, Petterson SC (2020) The changing face of orthopaedic education: searching for the new reality after COVID-19. Arthrosc Sport Med Rehabil 2(4):e295-e298. https:// doi.org/10.1016/j.asmr.2020.04.007

12. Ong MTY, Ling SKK, Wong RMY et al (2020) Impact of COVID19 on orthopaedic clinical service, education and research in a university hospital. J Orthop Transl 25(July):125-127. https://doi. org/10.1016/j.jot.2020.08.001

13. Upadhyaya GK, Jain VK, Iyengar KP, Patralekh MK, Vaish A (2020) Impact of COVID-19 on post-graduate orthopaedic training in Delhi-NCR. J Clin Orthop Trauma 11:S687-S695. https:// doi.org/10.1016/j.jcot.2020.07.018

14. Bhashyam AR, Dyer GSM (2020) "Virtual" boot camp: orthopaedic intern education in the time of COVID-19 and beyond. $J$ Am Acad Orthop Surg 28(17):e735-e743. https://doi.org/10.5435/ JAAOS-D-20-00559

15. Fagen AP, Crouch $\mathrm{CH}$, Mazur E (2002) Peer instruction: results from a range of classrooms. Phys Teach 40(4):206-209. https:// doi.org/10.1119/1.1474140

16. Crouch CH, Mazur E (2001) Peer instruction: ten years of experience and results. Am J Phys 69(9):970-977. https://doi.org/10. $1119 / 1.1374249$

17. Lasry N, Mazur E, Watkins J (2008) Peer instruction: from Harvard to the two-year college. Am J Phys 76(11):1066-1069. https://doi.org/10.1119/1.2978182

18. Butler BA, Butler CM, Peabody TD (2019) Cognitive apprenticeship in orthopaedic surgery: updating a classic educational model. J Surg Educ 76(4):931-935. https://doi.org/10.1016/j.jsurg.2019. 01.009

19. Costa ML, Van Rensburg L, Rushton N (2007) Does teaching style matter? A randomised trial of group discussion versus lectures in orthopaedic undergraduate teaching. Med Educ 41(2):214-217. https://doi.org/10.1111/j.1365-2929.2006.02677.x

20. Sadideen H, Kneebone R (2012) Practical skills teaching in contemporary surgical education: How can educational theory be applied to promote effective learning? Am J Surg 204(3):396-401. https://doi.org/10.1016/j.amjsurg.2011.12.020

21. Ibrahim EF, Richardson MD, Nestel D (2015) Mental imagery and learning: a qualitative study in orthopaedic trauma surgery. Med Educ 49(9):888-900. https://doi.org/10.1111/medu.12759

22. Losco M, Familiari F, Giron F, Papalia R (2017) Use and effectiveness of the cadaver-lab in orthopaedic and traumatology education: an Italian survey. Joints 5(4):197-201. https://doi.org/10. 1055/s-0037-1608949

23. James HK, Pattison GTR, Griffin DR, Fisher JD (2020) How does cadaveric simulation influence learning in orthopedic residents? J Surg Educ 77(3):671-682. https://doi.org/10.1016/j.jsurg.2019. 12.006
24. Bartlett JD, Lawrence JE, Stewart ME, Nakano N, Khanduja V (2018) Does virtual reality simulation have a role in training trauma and orthopaedic surgeons? Bone Jt J 100B(5):559-565. https://doi.org/10.1302/0301-620X.100B5.BJJ-2017-1439

25. Pearce O, Edwards T, Al-Hourani K, Kelly M, Riddick A (2021) Evaluation and Management of Atypical Femoral Fractures: An Update of Current Knowledge. Eur J Orthop Surg Traumatol. https://doi.org/10.1007/s00590-021-02896-3

26. Kuršumović K, Hadeed M, Bassett J et al (2021) Lateral compression type 1 (LC1) pelvic ring injuries: a spectrum of fracture types and treatment algorithms. Eur J Orthop Surg Traumatol. https:// doi.org/10.1007/s00590-021-02935-Z

27. Iliadis AD, Shivji F, Debuka E et al (2021) Current concepts in the prevention, diagnosis and treatment of fracture-related infection (FRI). Eur J Orthop Surg Traumatol. https://doi.org/10.1007/ s00590-021-02956-8

28. Khwaja A, Mahoney W, Johnson J et al (2021) Biomechanics of periprosthetic femur fractures and early weightbearing. Eur J Orthop Surg Traumatol. https://doi.org/10.1007/ s00590-021-02969-3

29. Grant M, Mehdian-Staffell R, Webb M et al (2021) Hip fractures in the young polytrauma patient: a review and the latest data from the UK. Eur J Orthop Surg Traumatol. https://doi.org/10.1007/ s00590-021-02923-3

30. Leow JM, Clement ND, McQueen MM et al (2021) The rate and associated risk factors for acute carpal tunnel syndrome complicating a fracture of the distal radius. Eur J Orthop Surg Traumatol. https://doi.org/10.1007/s00590-021-02975-5

31. Duffy S, Flannery O, Gelfer Y et al (2021) Overview of the contemporary management of supracondylar humeral fractures in children. Eur J Orthop Surg Traumatol. https://doi.org/10.1007/ s00590-021-02932-2

32. Duffy S, Gelfer Y, Trompeter A et al (2021) The clinical features, management options and complications of paediatric femoral fractures. Eur J Orthop Surg Traumatol. https://doi.org/10.1007/ s00590-021-02933-1

33. Murphy D, Raza M, Monsell F, Gelfer Y (2021) Modern management of paediatric tibial shaft fractures: an evidence-based update. Eur J Orthop Surg Traumatol. https://doi.org/10.1007/ s00590-021-02988

34. Khan H, Green G, Arnander M et al (2021) What are the risk factors and presenting features of premature physeal arrest of the distal radius? A systematic review. Eur J Orthop Surg Traumatol. https://doi.org/10.1007/s00590-021-02952-y

35. Vipulendran K, Kelly J, Rickman M et al (2021) Current concepts: managing acetabular fractures in the elderly population. Eur J Orthop Surg Traumatol. https://doi.org/10.1007/ s00590-021-02931-3

36. Laubscher M, Ferreira N, Birkholtz FF et al (2021) Civilian gunshot injuries in orthopaedics: a narrative review of ballistics, current concepts, and the South African experience. Eur J Orthop Surg Traumatol. https://doi.org/10.1007/s00590-021-02934-0

37. Ferreira N, Saini AK, Birkholtz FF et al (2021) Management of segmental bone defects of the upper limb: a scoping review with data synthesis to inform decision making. Eur J Orthop Surg Traumatol. https://doi.org/10.1007/s00590-021-02887-4

38. Weil S, Fontalis A, Guessoum M et al (2021) Augmented compression in exchange nailing for femoral and tibial non-unions accelerates time to radiographic union. Eur J Orthop Surg Traumatol. https://doi.org/10.1007/s00590-021-02900-w

39. Griffiths A, Dixon J, Egglestone A et al (2021) Evidence-based orthopaedic trauma care in the United Kingdom: guidelines, registries, carrots and sticks. Eur J Orthop Surg Traumatol. https:// doi.org/10.1007/s00590-021-02954-w

40. Raza M, Houston J, Geleit R et al (2021) The use of ionising radiation in orthopaedic surgery: principles, regulations and 
managing risk to surgeons and patients. Eur J Orthop Surg Traumatol. https://doi.org/10.1007/s00590-021-02955-9

41. Farhan-Alanie MM, Dhaif F, Trompeter A et al (2021) The risks associated with tourniquet use in lower limb trauma surgery: a systematic review and meta-analysis. Eur J Orthop Surg Traumatol. https://doi.org/10.1007/s00590-021-02957-7
Publisher's Note Springer Nature remains neutral with regard to jurisdictional claims in published maps and institutional affiliations. 